\title{
Which Motivational Factors are of More Relevance to the Rural Health Worker? Evidence from a Ghanaian District Hospital
}

\section{Emmanuel Kumah}

Institute of Management, Scuola Superiore Sant Anna, Piazza Martiri della Libertà, 33, Pisa PI Italy.

*Corresponding author: Emmanuel Kumah, Institute of Management, Scuola Superiore Sant Anna, Piazza Martiri della Libertà, 33, Pisa PI Italy, Tel: +393319947428; E-mail: ababiohemmanuel@gmail.com

Received date: March 20, 2017; Accepted date: March 31, 2017; Published date: April 07, 2017

Copyright: (c) 2017 Kumah E. This is an open-access article distributed under the terms of the Creative Commons Attribution License, which permits unrestricted use, distribution, and reproduction in any medium, provided the original author and source are credited.

\begin{abstract}
Introduction: Motivation of health professionals is one of the key ways to ensuring efficient provision of health services. Improving the motivation of health workers in rural and remote areas is of greatest concern to all countries worldwide. Even though factors influencing health worker motivation are well established in the literature, little is known about the motivational factors that are of relevance to different categories of rural health workers in developing countries.

Objectives: Employing questionnaire survey, we studied 252 health employees of a rural healthcare organization in Northern Ghana to understand the motivational factors that are considered most important by rural health workers, and to determine if these factors are valued differently by different cadres of health professionals.

Results: Our findings showed financial rewards as the number one motivator; followed by promotion, growth and development; job security; acknowledgement, praise and recognition; and working environment in that order. Different cadres of the rural health professionals valued the motivational factors differently: doctors were motivated by their working environment; nurses by promotion, growth and development; pharmacists and pharmacy technicians by praise, acknowledgement and recognition; and support staff and laboratory technicians by financial rewards.
\end{abstract}

Conclusion: Motivational factors should be applied to different cadres of rural health workers differently.

Keywords: Job motivation; Rural health worker; Developing country; Motivational factors

\section{Introduction}

Motivation is the main source of employees' satisfaction with their job. The availability of motivated health professionals is essential for adequate and efficient provision of health services in all countries [1]. As asserted by a body of literature [2,3], health professionals are at the heart of every country's health system and adequately motivated workforce is the prerequisite for a functioning health system. In the absence of adequately motivated staff, modern and sophisticated medical equipment as well as effective health care procedures would not function effectively [4]. The presence of de-motivated workforce results in poor work attitudes and increased absenteeism in healthcare organizations.

Understanding employee motivation is necessary to design systems with the right incentives [5].

Many factors, ranging from available physical infrastructure to an individual's personal values, are known to influence the motivation of health workers [6]. However, while factors influencing health worker motivation are well established in the literature; little is known about the motivational factors that are of relevance to health professionals in developing countries [7] particularly those in rural and resource poorsettings $[8,9]$.
Health problems are bigger in rural areas, where almost $60 \%$ of most developing countries' population lives. Health professionals in these areas often face higher workloads, poor infrastructure and unsustainable work environments, making their motivation and job satisfaction very essential for efficient healthcare delivery [10] Gaining a better insight into the way rural health workers perceive workplace motivation and the importance they give to the various motivational factors will be necessary in the development of effective strategies to enhance health worker motivation in rural healthcare organizations. Thus, we studied the employees of a rural district hospital in Ghana to:

1) Understand the motivational factors that are of relevance to rural health workers, and

2) Determine if different cadres of health workers value motivational factors differently.

\section{Study context}

The West Gonja Hospital is situated in the West Gonja District of the Northern Region of Ghana. It is a rural mission hospital under the private-not-for-profit category of the health delivery systems in Ghana. It has a bed capacity of 100 and provides the following services:

24 hour emergency care,

OPD, and inpatient services,

laboratory services, 
radiological services,

eye care services,

reproductive and child health services, and

anti-retroviral treatment (ART)/prevention of mother to child transmission (PMCT) services).

The facility was established by a farming company (Workers' Brigade), as a clinic to provide the basic health needs of its employees and dependents.

In 1954, the Catholic Church took over the administration of the hospital. Presently, the hospital is under the leadership of the National Catholic Health Service. The facility has total staff strength of 252 and serves over 200 thousand inhabitants.

\section{Theoretical underpinning}

This study was guided by Maslow's Hierarchy of Needs Theory. Maslow [11] asserts that there are five categories of individual needs: self-actualization (the need for personal growth and development), esteem (the need for status, self-respect etc.), social needs (love, affection and belongingness), safety needs (job security) and physiological needs (food, clothing and shelter).

These needs are grouped into two levels: lower order (basic), and higher order (less basic) needs. According to Maslow, the lower order needs are satisfied externally (offering extrinsic rewards) while the higher order needs are met internally (giving intrinsic rewards).

Based on Maslow's theory and a body of literature on what motivates rural health workers $[10,12,13]$ we used five motivational themes in this study.

These are: financial rewards (physiological need); promotion, growth and development (self-actualization need); job security (safety need); working environment (both physiological need- physical environment, and social need- social environment); and praise acknowledgement and recognition (esteem need).

\section{Methods}

A cross-sectional survey, using self-administered questionnaire, was conducted among 252 employees of the study hospital.

Based on the literature on rural health worker motivation, we developed a questionnaire for the study.

The questionnaire consisted of two parts.

The first part was made up of five closed-ended questions designed to collect demographic data of the respondents. Five-point Likert scale was used to design the second part of the instrument.

Respondents were asked to rate the extent to which they were motivated by the five motivational themes. Response options ranged from 'Highly motivated' to 'not motivate'.

The instrument was examined by 10 scholars and experts in the field of management and their constructive views were duly considered in refining the tool.

To ensure the validity and reliability of the research instrument, we pre-tested the questionnaire before the final administration. Similar responses were given to both the pre-tested and the actual administered questionnaire.

Questionnaire administration was done on-site. We visited the hospital, and after obtaining permission from the authorities, we entered each department and distributed the questionnaires to the respondents.

Before administration, we made sure that all the sections, including the questions, were well explained to each respondent.

This was done to: reduce respondent errors, avoid the incidents of skipped questions, and increase the overall response rate. Respondents were given one week each to record their responses and return the questionnaires.

\section{Data analysis}

Demographic characteristics of the respondents were analyzed descriptively (mainly percentages). We scored responses to the Likert items assessing the extent to which the respondents were motivated by the five motivational themes as follows: Highly motivated $=5$, Motivated $=4$, Neutral $=3$, Lowly motivated $=2$, and Not motivated $=1$. These scores were summed up for the respective items and converted into averages to represent the overall mean scores of the motivational themes.

We used STATA software package (version 13.0) for the analysis.

\section{Ethical Issues}

We obtained approval from both the National Catholic Health Service (NCHS) of Ghana (the supervisory body of the West Gonja Hospital) and management of the hospital before commencing the study.

All of the respondents were provided with adequate information, which enabled them to give their informed consent before we started collecting data from them.

\section{Results}

\section{Descriptive results}

Out of the 252 employees surveyed, 220 returned their fully completed questionnaires, giving a response rate of $87.3 \%$. This was made up of $6 \%$ doctors, $36 \%$ nursing staff, $11 \%$ pharmacists and pharmacy technicians, $12 \%$ biomedical scientists and laboratory technicians and $35 \%$ support staff.

Male respondents were 64 constituting $58 \%$ of the total respondents while female respondents were 46 making up of $42 \%$ of the total respondents. The majority of the respondents were between 20 and 29 years $(47 \%)$.

In terms of years worked, $75 \%$ had spent less than 10 years, $13 \%$ had worked for more than 10 years, but less than 20 years, and 19\% had spent between 20 and 29 years working in the hospital.

For detailed information on the respondents' demographics, (Table $1)$.
Cumulative Percentage (\%) 
Citation: Kumah E (2017) Which Motivational Factors are of More Relevance to the Rural Health Worker? Evidence from a Ghanaian District Hospital. J Gen Pract (Los Angel) 5: 299. doi:10.4172/2329-9126.1000299

Page 3 of 5

\begin{tabular}{|c|c|c|c|}
\hline Age & & & \\
\hline $20-29$ & 102 & 47 & 47 \\
\hline $30-39$ & 56 & 25 & 72 \\
\hline $40-49$ & 26 & 12 & 84 \\
\hline $50-59$ & 34 & 16 & 100 \\
\hline \multicolumn{4}{|l|}{ Gender } \\
\hline Male & 128 & 58 & 58 \\
\hline Female & 92 & 42 & 100 \\
\hline \multicolumn{4}{|l|}{ Profession } \\
\hline Doctor & 12 & 6 & 6 \\
\hline Nurse & 80 & 36 & 42 \\
\hline Biomed. Scientist and Lab Tech & 26 & 12 & 54 \\
\hline Pharmacist and Pharmacy Tech & 24 & 11 & 65 \\
\hline Support Staff & 78 & 35 & 100 \\
\hline \multicolumn{4}{|l|}{ Years Worked } \\
\hline $0-9$ & 150 & 68 & 68 \\
\hline $10-19$ & 28 & 13 & 81 \\
\hline $20-29$ & 42 & 19 & 100 \\
\hline \multicolumn{4}{|l|}{ Level of Education } \\
\hline High School & 36 & 16 & 16 \\
\hline Diploma/Degree & 180 & 82 & 98 \\
\hline Postgraduate & 4 & 2 & 100 \\
\hline
\end{tabular}

Table 1: Demographic information of the respondents.

\begin{tabular}{|l|l|}
\hline Motivational Theme & Mean Score \\
\hline Financial rewards & 4.2 \\
\hline Promotion, growth and development & 3.9 \\
\hline Job security & 3.1 \\
\hline Praise, acknowledgement and recognition & 2.9 \\
\hline Working environment & 2.7 \\
\hline
\end{tabular}

Table 2: Mean scores of the five motivational themes $(n=220)$.

\section{Motivational factors}

Table 2 displays the order of importance and the mean scores of the five motivational themes. Financial rewards were considered the most important motivator (mean score $=4.2$ ); followed by promotion, growth and development (mean score $=3.9$ ); and job security (mean score=3.1). Praise, acknowledgement and recognition (mean score=2.9); and working environment (mean score=2.7) were considered by the respondents as the least important motivators. More male $(42 \%)$ than female (28\%) respondents, as well as respondents within the age range of 20 and 29 (63\%) were highly motivated by financial rewards. Respondents who were 50 years or older considered promotion, growth, and development the most important motivator ( $29 \%$ and $71 \%$ highly motivated and motivated respectively) (Table 2).

The motivational themes were valued differently by the different cadres of health professionals. Doctors were motivated by their working environment ( $83 \%$ highly motivated); nurses were motivated by promotion, growth and development $(12 \%$ highly motivated and $78 \%$ motivated); pharmacists and pharmacy technicians were 
motivated by praise, acknowledgement and recognition (25\% highly motivated and $75 \%$ motivated) while both the support staff $(59 \%$ highly motivated and $41 \%$ motivated) and the biomedical scientists and laboratory technicians (54\% highly motivated and $46 \%$ motivated) were motivated by financial rewards.

\section{Discussion and Conclusion}

Generally, the health workers considered financial rewards to be the most important motivator. This supports Frederick Taylor's Theory of Scientific Management, which asserts that workers are mainly motivated by financial incentives [14]. Our results also confirm other empirical findings [15-17], that health care employees are highly motivated by financial incentives. Financial rewards are lower order needs under Maslow's Needs Theory. Maslow [11], argues that lower order needs have to be met before moving on to satisfy higher order needs. Hence, in motivating the employees of West Gonja Hospital generally, financial rewards should be considered first, targeting the male health workforce and professionals aged between 20 and 29 years.

Our results disagree with the findings of other similar studies conducted in urban healthcare organizations. For instance, working environment which was ranked fifth in our study was ranked second by Awases et al. [17] and third by Willis-Shattuck et al. [16]. The second ranked motivator in this study, promotion, growth and development, was ranked third by Agyepong et al. [18]. Employee development was not ranked as an important motivating factor by Awases et al. [17], but was part of the second most important motivator in this study. These differences suggest that the setting of care (urban, rural etc.) could play a significant role in factors impacting on health worker motivation.

Our finding that the different rural health professionals valued some motivational factors more important than others might be influenced by certain factors. Doctors are one group of employees with better conditions of service in Ghana. They have been noted to be among the highest paid health workers in Africa $[19,20]$. This might explain why they were no longer highly interested in financial rewards, but in improved working environment. The next important health employees to doctors are nurses. These health professionals are also well paid. Thus, their physiological needs seemed satisfied [11]. Pharmacists and pharmacy technicians also receive better financial incentives. This might be the reason why praise, acknowledgement and recognition were considered an important motivator by this group of health employees. In terms of pay, support staff in Ghanaian hospitals is the lowest paid employees. It was thus not surprising that they considered financial rewards the most important motivator. The findings support Maslow' assertion that employees should be motivated based on needs [11].

Our study is not without limitations. The primary limitation pertains to the small sample size we employed. A large sample would have been appropriate, but this could not be possible as no funding was secured for the study. This did not however make it impossible in obtaining useful findings. A secondary limitation is that the study was conducted in only one health care organization located in a particular geographical location in Ghana. The findings may therefore have limited generalizability. That notwithstanding, because health care organizations in rural Ghana have similar working conditions, the findings would be relevant to other rural health care institutions in the country.
In summary, our study has identified the motivational factors considered most important by different cadres of rural health professionals. To achieve adequate motivation for a greater proportion of rural health workforce, policy makers and healthcare managers need to take these factors into account when designing and implementing rural health worker motivational programs.

\section{References}

1. Dieleman M, Harnmeijer JW (2006) Improving health worker performance: In search of promising practices. WHO, Geneva.

2. Kanfer R (2009) Work motivation: identifying new use-inspired research direction. Ind Org Psych: Perspectives on Sci and Prac 2: 77-93.

3. Buchan J (2005) Scaling up health and education workers: Increasing the performance and productivity of an existing stock of health workers, Dep for Int Dev Hlth Resource Centre London, pp- 23.

4. Suliman AB, Al-Sabri N (2009) Surviving through the global downturns: Employee motivation and retention in healthcare industry. The Open Bus J 2: 86-94.

5. Mbindyo PM, Blaauw D, Gilson L, English M (2009) Developing a tool to measure health worker motivation in district hospitals in Kenya. Hum Resour Health 7-40.

6. Rowe AK, de Savigny D, Lanata CF, Victora CG (2005) How can we achieve and maintain high-quality performance of health workers in lowresource settings? Lancet 366: 1026-1035.

7. Malik AZ, Yamamoto SS, Souares A, Malik Z, Sauerborn R (2010) Motivational determinants among physicians in Lahore, Pakistan. BMC Health Serv Res 10: 1186-1472.

8. Dieleman M, Cuong PV, Martineau T (2003) Identifying factors for job motivation of rural health workers in North Viet Nam. Hum Resour Health 1:10.

9. Franco L M, Bennett S, Kanfer R (2002) Health sector reform and public sector health worker motivation: a conceptual framework. Soc Sci Med 54: $1255-1266$.

10. Agyei-Baffour P, Kotha SR, Johnson, JC, Gyakobo M, Asabir K, Kwansah J, et al. (2011) Willingness to work in rural areas and the role of intrinsic versus extrinsic professional motivation-a survey of medical students of Ghana. BMC Med Edu 11: 27.

11. Maslow AH (1995) Motivation and personality. Harper \& Row, New York, USA.

12. (2010) World Health Organization. Increasing access to health workers in remote and rural areas through improved retention: global policy recommendations. Geneva: World Health Organization.

13. Dieleman M, Gerretsen B, Wilt GV (2009) Human resource management interventions to improve health workers' performance in low and middle income countries, a realist review, Health Research Policy and Systems 7.

14. (1911) Taylor FW. Scientific management. New York: Harper.

15. Adzei FA, Atinga RA (2012) Motivation and retention of health workers in Ghana's district hospitals: Addressing the critical issues". J Health Org Manage 26: 467-485.

16. Willis-Shattuck M, Bidwel P, Thomas S, Wyness L, Ditlopo P (2008) Motivation and retention of health workers in developing countries: a systematic review, BMC Health Serv Res 8: 247.

17. Awases M, Gibary A, Nyoni J, Chatora R (2004) Migration of health professionals in countries: A synthesis report. WHO Regional Office of Africa.

18. Agyepong IA, Anafi P, Asiamah E, Ansah EK, Ashon D, et al. (2004) Health worker satisfaction and motivation in the public sector in Ghana. Int J Health Plann Mgmt 19: 319-336.

19. Amoako P (2011) Identifying pull and push factors of health workers in rural Ghana, a case study of Mpohor Wassa District in the Western Region. Department of Economics: KNUST. 
Citation: Kumah E (2017) Which Motivational Factors are of More Relevance to the Rural Health Worker? Evidence from a Ghanaian District Hospital. J Gen Pract (Los Angel) 5: 299. doi:10.4172/2329-9126.1000299

Page 5 of 5

20. Anarfi J, Quartey P, Agyei J (2010) Key determinants of migration among professionals in Ghana. Development Research Centre on Migration, Globalization and Poverty.

This article was originally published in a special issue, entitled: "Rural Health Development", Edited by Emmanuel Kumah 